\title{
Effect of tryptophan on the early tri-iodothyronine uptake in mouse thymocytes
}

\author{
M Centanni ${ }^{1,2}$, G Canettieri ${ }^{1}, \mathrm{~N}$ Viceconti ${ }^{1}, \mathrm{R} \mathrm{Sibilla}^{1}, \mathrm{~A} \mathrm{Bei}^{1}$ and M Andreoli ${ }^{1,2}$ \\ ${ }^{1}$ Department of Experimental Medicine and Pathology, University 'La Sapienza' of Rome, Italy and ${ }^{2}$ Institute of Experimental Medicine, \\ Consiglio Nazionale Richerche, Rome, Italy
}

(Correspondence should be addressed to M Centanni, Department of Experimental Medicine and Pathology, Policlinico Umberto I ${ }^{\circ}$ O0161 Roma, Italy; Fax: +39-06-49972606)

\begin{abstract}
Objective: We have studied the effect of tryptophan on cellular $\left[{ }^{125} \mathrm{I}\right]$ tri-iodothyronine (T3) uptake by mouse thymocytes.

Materials and methods: Mouse thymocytes $\left(20 \times 10^{6}\right.$ cells/ml) were suspended in Krebs-Ringer solution buffered by Tris- $\mathrm{HCl}$ and incubation $\left(23^{\circ} \mathrm{C}\right.$ at $\left.\mathrm{pH} 7.45 \pm 0.6\right)$, in the presence or absence of $1 \mathrm{mM}$ tryptophan, was started by adding $25 \mathrm{pM}\left[{ }^{125} \mathrm{I}\right] \mathrm{T} 3$. At the end of incubation, samples were cooled in ice, centrifuged over a $30 \%$ sucrose cushion and the cell-associated radioactivity was measured in the pellet.

Results: Tryptophan reduced both the total and the saturable fraction of $\left[{ }^{125} \mathrm{I}\right] \mathrm{T} 3$ uptake by $44 \%$ $(P=0.0009)$ and $60 \%(P=0.0006)$ respectively, following $1 \mathrm{~min}$ of incubation. This effect was specific and dose-dependent, being maximal at $5 \mathrm{mM}$ concentration $(-82 \%)$. In contrast, the preexposure of cells to tryptophan for up to $2 \mathrm{~h}$ had no effect on the subsequent uptake of $\left[{ }^{125} \mathrm{I}\right] \mathrm{T} 3$, in the absence of tryptophan. The effect of D-tryptophan on saturable T3 uptake was not different from that obtained using the L-stereoisomer. Tryptophan reduced the $V_{\max }$ of the initial rate of saturable $\left[{ }^{125} \mathrm{I}\right] \mathrm{T} 3$ uptake by two-thirds without affecting the apparent $K_{\mathrm{m}}(2.2 \mathrm{nM})$ of the process, thus indicating the non-competitive nature of the inhibition. In sodium-free medium the saturable $\left[{ }^{125} \mathrm{I}\right] \mathrm{T} 3$ uptake was reduced by $43 \%$. The inhibitory effect of tryptophan on $\left[{ }^{125} \mathrm{I}\right] \mathrm{T} 3$ uptake was exerted in both the presence and the absence of sodium. In fact, the inhibitory effect of tryptophan on T3 transport was greater and significantly different $(P=0.0046)$ from that obtained by sodium depletion alone. Conclusions: Tryptophan interferes with both the sodium-dependent and -independent components of $\left[{ }^{125} \mathrm{I}\right] \mathrm{T} 3$ uptake by a dose-dependent, non-competitive mechanism which operates in cis-modality at the plasma membrane level of mouse thymocytes.
\end{abstract}

European Journal of Endocrinology 143 119-123

\section{Introduction}

Due to the intracellular localization of thyroid hormone receptors, iodothyronines must enter the cells to exert their biological actions. Several studies have focused on tri-iodothyronine (T3) and thyroxine (T4) entry mechanism into different cell types of rodents $(1-7)$ and humans $(8,9)$; these have shown the existence of a regulatory mechanism at the plasma/cell interface. The mechanism, depending on the tissue studied, appears to operate both for T3 and T4 $(1,4,5,7-9)$ or T3 only (2, $3,6)$. Despite some biochemical differences, almost all the mechanisms described for thyroid hormone transport showed analogies to some systems which mediate amino acid transport into cells (10-12). In mouse thymocytes, we have previously shown that a saturable, $\mathrm{pH}$ - and partly $\mathrm{Na}^{+}$-sensitive mechanism mediates $\mathrm{T} 3$ entry (13). This process seemed to share several biochemical characteristics with the amino acid transport system ASC for neutral amino acids (10). In different tissues, the involvement of amino acid transport systems L or $\mathrm{T}$ (14-17), based on the effect of tryptophan and/or leucine on the rate of $\mathrm{T} 3$ or $\mathrm{T} 4$ transport, have been reported (14-17). In particular, the existence of a close relationship between tryptophan and T3 transport at the plasma membrane has been described in erythrocytes and cultured astrocytes (14, 15). Moreover, these interactions seem to be modulated by thyroid status in vivo (18). In mouse thymocytes, where over four-fifths of T3 bound to the nucleus derive directly from plasma (19), the role of transport systems at the plasma membrane level may be relevant to the intracellular fate of iodothyronines. The purpose of the present study was therefore to evaluate the effect of tryptophan on early T3 uptake by mouse thymocytes. 
Table 1 Effect of tryptophan stereoisomer on $\left[{ }^{125} \mathrm{I}\right] \mathrm{T} 3$ uptake. The uptake is expressed as $\%\left[{ }^{125} \mathrm{I}\right] \mathrm{T} 3 / 10^{6}$ cells and the data represent the means \pm S.D. of four different experiments.

\begin{tabular}{|c|c|c|c|c|c|}
\hline & & Total uptake & Variation & $P$ & $\boldsymbol{P}^{*}$ \\
\hline (a) & Basal & $1.62 \pm 0.22$ & - & - & - \\
\hline (b) & Plus excess T3 & $0.50 \pm 0.07$ & -69 & $<0.0001$ & - \\
\hline \multirow[t]{3}{*}{ (c) } & Plus L-tryptophan & $0.91 \pm 0.13$ & -44 & 0.0009 & - \\
\hline & Plus excess T3+ L-tryptophan & $0.53 \pm 0.09$ & -67 & $<0.0001$ & $n s^{1}$ \\
\hline & Plus D-tryptophan & $1.01 \pm 0.12$ & -38 & 0.0019 & $n s^{2}$ \\
\hline
\end{tabular}

Cells were incubated with $25 \mathrm{pM}\left[^{125} \mathrm{I}\right] \mathrm{T} 3$ for $1 \mathrm{~min}$ at $23^{\circ} \mathrm{C}$, with the variables listed above. $1 \mathrm{mM} \mathrm{D}$ - and L-tryptophan were used throughout. Excess unlabelled T3 added was $15 \mu \mathrm{M}$.

$P=$ using (a) as reference value; $P^{* 1}=$ using (b) as reference value; $P^{* 2}=$ using (c) as reference value. ns, not significant.

\section{Materials and methods}

\section{Chemicals}

All chemicals were reagent grade and were obtained from Sigma (St Louis, MO, USA). $\left[{ }^{125} \mathrm{I}\right] \mathrm{T} 3$ (specific activity $3300 \mu \mathrm{Ci} / \mu \mathrm{g}$ ) was obtained from New England Nuclear (Florence, Italy). The purity of labelled T3 was tested by thin-layer chromatography on silica gel plates using a mixture (1:3:16) of formic acid/methanol/ chloroform as in Sato \& Cahnmann (20). Negligible deiodination occurred in all the conditions assayed.

\section{Cell preparation and cellular uptake measurements}

Isolated thymocytes were obtained from BALB-c mice, 3-6 weeks old, housed and fed using standardized procedures. Isolation of thymocytes was performed as previously described (21). Cell viability was tested before and after experiments and, as assessed by trypan blue dye exclusion, was always greater than 95\%. Isolated cells were suspended in modified Krebs-Ringer solution buffered by Tris- $\mathrm{HCl}$ at physiological $\mathrm{pH}$, as previously described (3). Preincubation, where appropriate, was carried out at $23{ }^{\circ} \mathrm{C}$, in the presence or absence of $1 \mathrm{mM}$ tryptophan, for 2,1 or $0.5 \mathrm{~h}$. In those experiments in which cells were pre-exposed to tryptophan, the amino acid was removed by washing the cells three times in incubation medium, before starting incubation with the labelled T3.

Incubation was started by adding tracer amounts $(25 \mathrm{pM})$ of $\left[{ }^{125} \mathrm{I}\right] \mathrm{T} 3$ to $1 \mathrm{ml}$ medium containing $20 \times 10^{6}$ cells. Incubation was performed at $23{ }^{\circ} \mathrm{C}$ for the times specified in the text, at $\mathrm{pH} 7.45 \pm 0.6$, in the presence or absence of $1 \mathrm{mM} \mathrm{L-}$ and/or D-tryptophan, unless otherwise specified. Experiments were stopped by cooling samples in ice and $3 \times 200 \mu \mathrm{l}$ aliquots were immediately removed and layered in a plastic microtube over an equal volume of $30 \%$ sucrose; samples were then centrifuged, and the radioactivity in the pellet counted to determine the total amount of labelled T3 associated with cells. The non-specific cell-associated radioactivity was measured as the $\left[{ }^{125} \mathrm{I}\right] \mathrm{T} 3$ uptake in the presence of $15 \mu \mathrm{M}$ unlabelled $\mathrm{T} 3$ and represented the non-saturable fraction of $\left[{ }^{125} \mathrm{I}\right] \mathrm{T} 3$ uptake. The saturable $\left[{ }^{125} \mathrm{I}\right] \mathrm{T} 3$ uptake was obtained by subtracting the non-saturable fraction from the total $\left[{ }^{125} \mathrm{I}\right] \mathrm{T} 3$ uptake and has been used throughout the study. In the experiments carried out in the absence of sodium, an iso-osmotic amount of choline chloride was added to the medium to replace sodium chloride.

All experiments were performed in triplicate and the results of at least three independent experiments were plotted. The INSTAT Graphpad software (199092) for DOS was used in the statistical analysis. Statistical analysis was performed by using the unpaired $t$-test or the Mann-Whitney test (two tailed) where appropriate.

\section{Results}

Total $\left[{ }^{125} \mathrm{I}\right] \mathrm{T} 3$ uptake following 1 min of incubation was $1.62 \pm 0.22 \% / 10^{6}$ cells and the non-saturable fraction of uptake represented $31 \%$ of the total (Table 1). The addition of L-tryptophan $(1 \mathrm{mM})$ during the incubation period significantly reduced total $\left[{ }^{125} \mathrm{I}\right] \mathrm{T} 3$ uptake at that time. The inhibitory effect of L-tryptophan and that of an excess of unlabelled $\mathrm{T} 3$ were not additive, indicating that the effect of that amino acid was exerted only on the saturable fraction of T3 uptake (Table 1). The nonsaturable fraction of $\left[{ }^{125} \mathrm{I}\right] \mathrm{T} 3$ uptake (see Materials and methods) was subtracted to obtain the saturable uptake, as previously described (3). The saturable $\left[{ }^{125} \mathrm{I}\right] \mathrm{T} 3$ uptake by thymocytes was linear in the first minute whereas the equilibrium between entry and exit rate was reached within $30 \mathrm{~min}$, similarly to previous studies (3) (not shown). Following $1 \mathrm{~min}$ of incubation, the saturable fraction of $\left[{ }^{125} \mathrm{I}\right] \mathrm{T} 3$ uptake was reduced by the simultaneous addition of $1 \mathrm{mM}$ L-tryptophan $(1.13 \pm 0.16 \mathrm{vs}$ $0.45 \pm 0.15 \% / 10^{6}$ cells; $\left.-60 \%, P=0.0006\right)$.

To investigate whether the inhibitory effect of tryptophan is exerted in cis, in trans or in both, thymocytes were preloaded up to $2 \mathrm{~h}$ in the presence of $1 \mathrm{mM}$ tryptophan, which was then removed before starting the incubation. The pre-exposure to tryptophan 


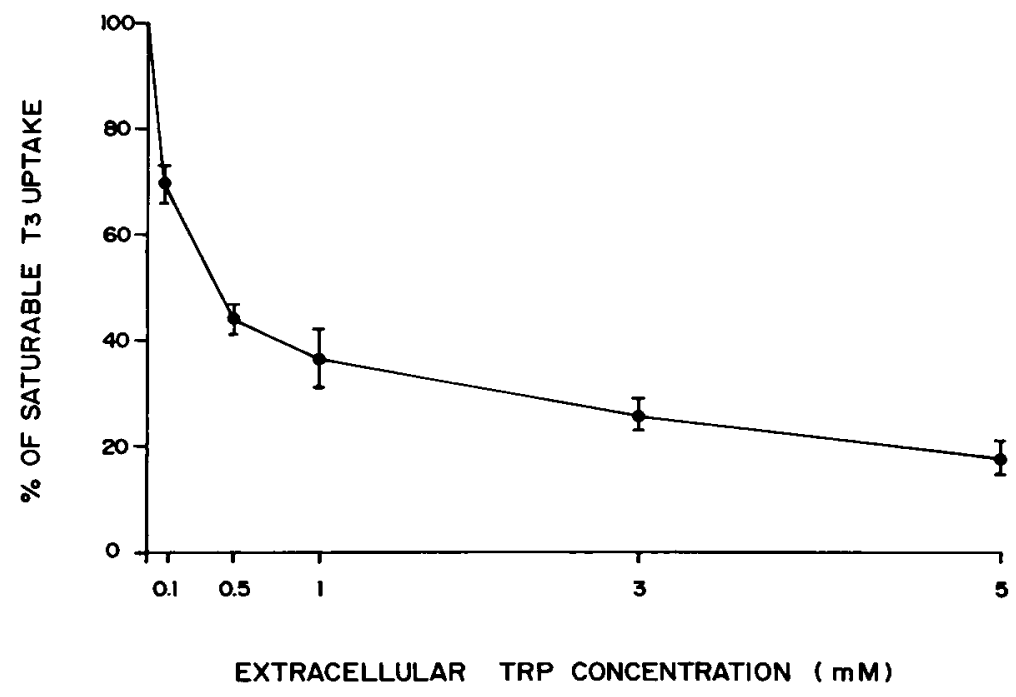

Figure 1 Dose-response curve of the effect of tryptophan on specific T3 uptake. Thymocytes were incubated with labelled T3 for $1 \mathrm{~min}$ at $23^{\circ} \mathrm{C}$ in the presence of different concentrations of tryptophan (TRP). Results, expressed as the percent of specific T3 uptake $/ 10^{6}$ cells, are the means \pm S.D. of five separate experiments. had no effect on the subsequent uptake of T3 $\left(1.58 \pm 0.23\right.$ vs $1.53 \pm 0.18 \% / 10^{6}$ cells; $P=$ not significant (ns)). This finding suggests that the effect of tryptophan is restricted to cis-inhibition at the T3 binding site on the outer membrane.

As the uptake of T3 by thymocytes has been proven to be stereospecific (3), the comparative effect of L- and Dtryptophan was investigated. The addition of $1 \mathrm{mM}$ Dtryptophan significantly reduced total $\left[{ }^{125} \mathrm{I}\right] \mathrm{T} 3$ uptake to an extent $(-38 \%)$ which was similar to that obtained with the L-stereoisomer (Table 1). The inhibitory effect of D-tryptophan on the saturable fraction of $\left[{ }^{125} \mathrm{I}\right] \mathrm{T} 3$ uptake $(-50 \% ; P=0.0061)$ was also similar to that obtained using the L-stereoisomer $\left(0.54 \pm 0.11 \% / 10^{6}\right.$ cells; $P=n s)$. This finding indicated that the effect of tryptophan is exerted on a structure not able to discriminate between amino acid enantiomers.
The described effect of L-tryptophan was dosedependent as shown in Fig. 1; in fact, the incubation of cells in the presence of increasing concentrations of the L-tryptophan $(0.1-5 \mathrm{mM})$ progressively reduced the amount of $\left[{ }^{125} \mathrm{I}\right] \mathrm{T} 3$ uptake to $18 \%$ of the control at the maximal concentration of tryptophan; the half maximal inhibitory concentration $\left(\mathrm{IC}_{50}\right)$ of tryptophan was about $0.35 \mathrm{mM}$.

The effect of L-tryptophan on the initial rate of $\left[{ }^{125} \mathrm{I}\right] \mathrm{T} 3$ uptake is shown in Fig. 2. The initial rate of T3 uptake, measured in the presence of increasing amounts of unlabelled T3 was saturable as already described (3) and was measured in the presence or absence of $1 \mathrm{mM}$ tryptophan. The rate of transport was analyzed by plotting the data according to the Eadie-Hofstee plot, in both the experimental conditions. This plot, shown in Fig. 2, revealed that the apparent $K_{\mathrm{m}}$ of $\left[{ }^{125} \mathrm{I}\right] \mathrm{T} 3$

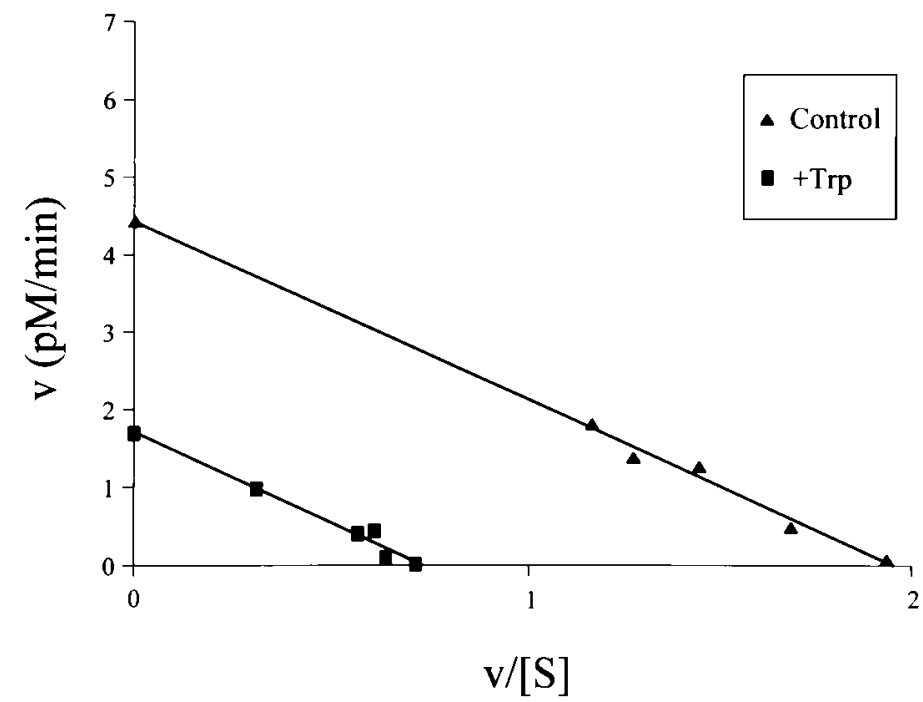

Figure 2 Effect of tryptophan on the initial rate of [ ${ }^{125}$ I]T3 uptake. Cells were incubated for $1 \mathrm{~min}$ with $25 \mathrm{pM}$ labelled $\mathrm{T} 3$, at $23^{\circ} \mathrm{C}$ and constant $\mathrm{pH}$, in the presence of increasing concentrations of unlabelled T3 with or without the addition of L-tryptophan (Trp; $1 \mathrm{mM})$. The rate of transport was analyzed by plotting the velocity of uptake $(\mathrm{v})$ vs the velocity of uptake/concentrations of T3 (v/[S]) according to the Eadie-Hofstee plot, in both experimental conditions. Each point represents the reciprocal of the mean of three separate experiments. 


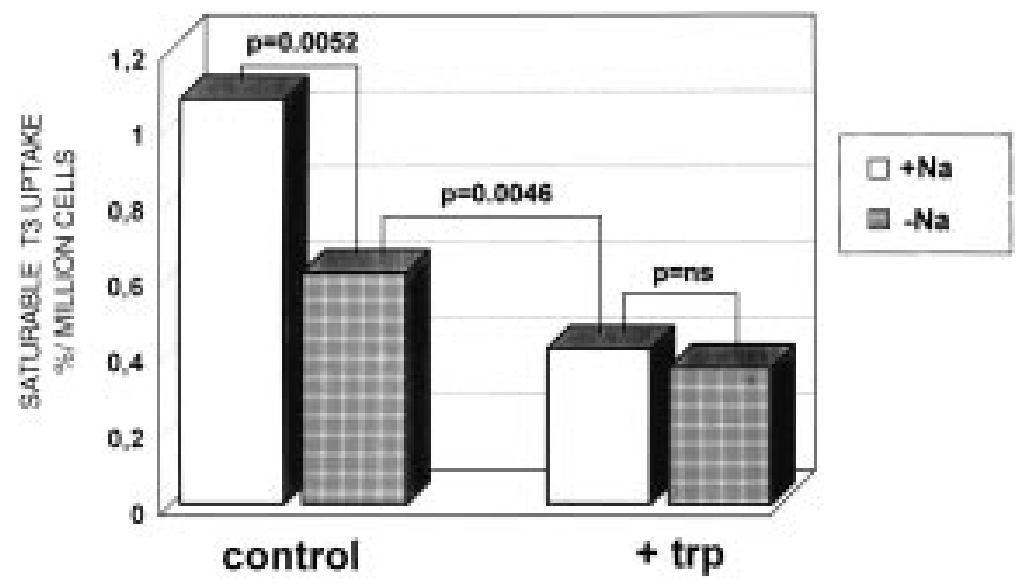

Figure 3 Combined effect of sodium depletion and tryptophan addition on ${ }^{125}$ I]T3 uptake. Cells were incubated in the presence or the absence of sodium, for $1 \mathrm{~min}$ at $23^{\circ} \mathrm{C}$ with or without tryptophan (trp; $1 \mathrm{mM}$ ). In $\mathrm{Na}^{+}$-free experiments sodium chloride was replaced by equal concentrations of choline chloride. The results, expressed as \% of specific T3 uptake/ $10^{6}$ cells, are the means \pm S.D. of four separate experiments. transport was $2.2 \mathrm{nM}$ and was not affected by the addition of tryptophan whereas the $V_{\max }$ was $4.5 \mathrm{pM} /$ $10^{6}$ cells per min and was reduced by about two-thirds (1.78 pM/10 ${ }^{6}$ cells per $\mathrm{min}$ ) by the addition of $\mathrm{L}-$ tryptophan. These parameters suggest a non-competitive inhibition between these two substrates.

The described carrier which facilitates T3 entry in thymocytes was reported to be partly dependent on extracellular sodium (14). The combined effect of sodium deprivation and tryptophan was therefore tested on cellular T3 uptake. The removal of extracellular sodium from the medium decreased the saturable $\left[{ }^{125} \mathrm{I}\right] \mathrm{T} 3$ uptake by $43 \%(P=0.0052)$ as compared with basal experimental conditions. The inhibition exerted on $\left[{ }^{125} \mathrm{I}\right] \mathrm{T} 3$ uptake, in the presence of sodium, by using $1 \mathrm{mM}$ tryptophan was greater and significantly different $(P=0.0046)$ from that obtained by sodium depletion alone (Fig. 3). The effect of tryptophan was already maximal as no further inhibition was obtained by combining the effect of the addition of tryptophan and that of the absence of sodium (Fig. 3).

\section{Discussion}

The results of this study indicate that tryptophan inhibits, in a dose-dependent fashion, the early saturable T3 uptake by mouse thymocytes to a considerably higher extent than reported in rat cardiac myocytes (7) and in choriocarcinoma cells (17) .

A close relationship among the T3 transport system and amino acid transport systems L and/or its variant $\mathrm{T}$ was reported in different tissues $(5,14-16,18)$ and the presence of a counter-transport mechanism shared by tryptophan and T3 has also been suggested in erythrocytes (14). In thymocytes, however, several biochemical characteristics of the effects of tryptophan were different from those previously reported $(5,14,15$, 17) and even the involvement of the T3 carrier described $(3,13)$ in that process may be questionable. In fact, the following peculiar findings emerged from the present investigation: (a) the effect of tryptophan on T3 uptake was evident only when both substrates (T3 and tryptophan) were present during incubation time; in contrast, in tryptophan-preloaded cells, when the incubation was carried out in the absence of tryptophan, no measurable inhibition was recorded. According to Guidotti et al. (10) and Christensen (12) it can be concluded that no trans-inhibition phenomena occurred and the effect of tryptophan was only exerted at the external T3-recognizing site at the plasma membrane level; (b) the initial rate of $\mathrm{T} 3$ influx in thymocytes was modified by tryptophan by changing the $V_{\text {max }}$ of the process, whereas the apparent $K_{\mathrm{m}}$ was not modified, indicating a non-competitive nature of the inhibitory process; (c) the inhibitory effect of tryptophan was not stereospecific since the D-form had the same effect as the L-form, whereas the described carrier for T3 in these cells was strongly stereospecific (3); (d) the inhibitory effect of tryptophan on T3 transport was exerted both in the presence and the absence of sodium. A similar effect was previously obtained in this tissue by changing the external $\mathrm{pH}$, whose variation inhibited $\left[{ }^{125} \mathrm{I}\right] \mathrm{T} 3$ uptake without discriminating between the sodium-dependent and sodium-independent component (13). Also, the coexistence of these two components of transport is typical of several transmembrane amino acids trafficking (12). However, tryptophan is usually transported into cells by a sodium-independent mechanism (22) and there is no evidence that it may interact with membrane structures related to ionic movements (10-12, 14, 22), thus suggesting that, in this tissue, its effect is exerted at more than one level on the plasma membrane.

These characteristics of the effect of tryptophan on the early $\left[{ }^{125} \mathrm{I}\right] \mathrm{T} 3$ uptake described above are unlikely to support the existence of a common transport system shared by tryptophan and T3 $(10,12)$.

A possible mechanism of tryptophan inhibition of $\mathrm{T} 3$ uptake by thymocytes may be similar to the one suggested by Kragie et al. (23). These authors showed, in an elegant study based on molecular modelling, that 
several substances, including those characterized by an alanine side chain and an outer phenyl ring, may conformationally block the iodothyronine membrane transporter. This interaction seems to be due to the thyromimetic action of these substances (23). Tryptophan is indeed an aromatic amino acid which is structurally similar to and shares the same transport system with tyrosine, the precursor of iodothyronines $(12,22)$; also, similarly to tryptophan in this study, thyroxine and thyronine inhibited L-T3 binding with the same $\mathrm{IC}_{50}$ in L- and D-conformations (23). Tryptophan may, therefore, induce a conformational change in the T3 membrane transporter that impairs its function (12). The kinetic characteristics of the effect of tryptophan on the saturable $\left[{ }^{125} \mathrm{I}\right] \mathrm{T} 3$ uptake (i.e. the non-competitive inhibition exerted only in cis modality, the lack of stereospecificity) may be consistent with this hypothesis, which does not imply a direct involvement of the plasma membrane T3 carrier described in thymocytes (3).

\section{Acknowledgements}

This project was supported by CNR, Institute of Experimental Medicine and Ministero dell'Università e della Ricerca Scientifica e Tecnologica, Italy.

\section{References}

1 Krenning E, Docter R, Bernard B, Visser TJ \& Hennemann G. Characteristics of active transport of thyroid hormone into rat hepatocytes. Biochimica et Biophysica Acta 1981676 314-320.

2 Centanni M \& Robbins J. Role of sodium in thyroid hormone uptake by rat skeletal muscle. Journal of Clinical Investigation 1987 80 1068-1072.

3 Centanni M, Mancini G \& Andreoli M. Carrier-mediated ${ }^{125}$ I T3 uptake by mouse thymocytes. Endocrinology $19891242443-$ 2448.

4 Francon J, Chantoux F \& Blondeau JP. Carrier-mediated transport of thyroid hormones into rat glial cells in primary culture. Journal of Neurochemistry 198953 1456-1463.

5 Zhou Y, Samson M, Francon J \& Blondeau JP. Thyroid hormone concentrative uptake in rat erythrocytes. Biochemical Journal $199228181-86$

6 Everts M, Docter R, van Buuren JCJ, van Koetsveld P, Hofland LJ, De Jong M, Krenning EP \& Hennemann G. Evidence for carriermediated uptake of triiodothyronine in cultured anterior pituitary cells of euthyroid rats. Endocrinology 1993132 1278-1285.

7 Everts M, Verhoeven F, Bezstarosti K, Moerings E, Hennemann G, Visser T \& Lamers JM. Uptake of thyroid hormones in neonatal rat cardiac myocytes. Endocrinology 1996137 4235-4242.

8 Docter R, Krenning EP. Bernard H \& Hennemann G. Active transport of iodothyronine into human cultured fibroblasts.
Journal of Clinical Endocrinology and Metabolism 198765 624628.

9 De Jong M, Visser TJ, Bernard B, Docter R, Vos R, Hennemann G \& Krenning EP. Transport and metabolism of iodothyronines in cultured human hepatocytes. Journal of Clinical Endocrinology and Metabolism 199377 139-144.

10 Guidotti GC, Borghetti AF \& Gazzola GC. The regulation of amino acid transport in animal cells. Biochimica et Biophysica Acta 1978 515 329-366.

11 Saier MH Jr, Daniels GA, Boerner P \& Lin J. Neutral amino acid transport systems in animal cells: potential targets of oncogene action and regulators of cellular growth. Journal of Membrane Biology 1988104 1-20.

12 Christensen HN. Role of amino acid transport and countertransport in nutrition and metabolism. Physiological Reviews $19907043-77$.

13 Centanni M, Sapone A, Taglienti A \& Andreoli M. Effect of extracellular sodium on thyroid hormone uptake by mouse thymocytes. Endocrinology 1991129 2175-2179.

14 Zhou Y, Samson M, Osty J, Francon J \& Blondeau JP. Evidence for a close link between the thyroid hormone transport system and the aromatic amino acid transport system $\mathrm{T}$ in erythrocytes. Journal of Biological Chemistry 1990265 17000-17004.

15 Blondeau JP, Beslin A, Chantoux F \& Francon J. Triiodothyronine is a high-affinity inhibitor of amino acid transport system L1 in cultured astrocytes. Journal of Neurochemistry $1993601407-$ 1413.

16 Lakshmanan M, Goncalves E, Lessly G, Foti D \& Robbins J. The transport of thyroxine into mouse neuroblastoma cells, NB41A3: the effect of L-system amino acids. Endocrinology 1990126 3245-3250.

17 Prasad PD, Leibach F, Mahesh V \& Ganapathy V. Relationship between thyroid hormone transport and neutral amino acid transport in JAR human choriocarcinoma cells. Endocrinology $1994134574-581$.

18 Kemp HF \& Taylor PM. Interactions between thyroid hormone and tryptophan transport in rat liver are modulated by thyroid status. American Journal of Physiology 1997272 E809-E816.

19 Van Doorn J, Roelfsema F \& van der Heide D. Concentrations of thyroxine and 3,5,3'-triiodothyronine at 34 different sites in euthyroid rats as determined by an isotopic equilibrium technique. Endocrinology 1985117 1201-1208.

20 Sato K \& Cahnmann H. Synthesis of 3,5- ${ }^{125}$ I triiodothyronine of high specific activity. Analytical Biochemistry 1980102 237-242.

21 Segal J \& Ingbar SH. Stimulation by triiodothyronine of the in vitro uptake of sugars by rat thymocytes. Journal of Clinical Investigation $197963507-515$.

22 Rosemberg R, Young JD \& Ellory JC. L-tryptophan transport in human red blood cells. Biochimica et Biophysica Acta 1980598 375-384.

23 Kragie L, Forrester ML, Cody V \& McCourt M. Computer-assisted molecular modeling of benzodiazepine and thyromimetic inhibitors of the HepG2 iodothyronine membrane transporter. Molecular Endocrinology 19948 382-391.

Received 13 September 1999

Accepted 13 March 2000 